DOI: https://doi.org/10.11144/Javeriana.umed59-4.fpom

\title{
Frequency of Oral and Maxillofacial Pathologies in Patients from 0 to 18 Years in the Fundación Hospital de la Misericordia Bogotá (Colombia), during the Period 2006-2014
}

\section{Frecuencia de patologías orales y maxilofaciales en pacientes de 0 a 18 años de la Fundación Hospital de la Misericordia, Bogotá (Colombia), durante el periodo 2006-2014}

Received: February 052018 | Accepted: July 242018

\author{
Erika Alexandra Parra Sanabria ${ }^{a}$ \\ Universidad Nacional de Colombia, Colombia \\ Claudia Patricia Peña Vega ${ }^{1}$ \\ Universidad Nacional de Colombia, Colombia
}

a Correspondence: eraparrasa@unal.edu.co

1 Odontologist, Pontificia Universidad Javeriana, Bogotá, Colombia. Oral and Maxillofacial Surgeon, Universidad Nacional de Colombia. Oral Pathologist, Pontificia Universidad Javeriana. Associate Professor, School of Dentistry, Universidad Nacional de Colombia

How to cite: Parra Sanabria EA, Peña Vega CP. Frequency of Oral and Maxillofacial Pathologies in Patients from 0 to 18 Years in the Fundación Hospital de la Misericordia Bogotá (Colombia), during the Period 2006-2014. Univ. Med. 2018;59(4). doi: https://doi.org/10.11144/Javeriana.umed59-4.fpom

\begin{abstract}
Introduction: Oral pathologies that can occur in children are very diverse and require extensive knowledge to diagnose them. Objective: To describe the frequency of oral and maxillofacial pathologies that occurred in patients aged 0-18 years who attended the Fundación Hospital de la Misericordia (HOMI) in the period 2006-2014, in addition to relating the most frequent oral and maxillofacial pathologies with sociodemographic characteristics. Materials and Methods: Descriptive, cross-sectional study. The analysis of information was recorded of 277 clinical histories of the HOMI, in patients from 0 to 18 years, who were diagnosed with any of the oral and maxillofacial pathologies, divided as follows: Head/ neck cystic lesions, temporomandibular joint (TMJ) lesions, infectious lesions, benign tumor, malignant tumor of head and neck, and benign odontogenic tumor. It was carried out in analysis of the sociodemographic characteristics. Results: The most frequent pathologies were infectious lesions (62.45\%), followed by benign odontogenic tumors (12.99\%). Conclusions: This study shows that the most frequent pathologies were infectious lesions and benign odontogenic tumors.
\end{abstract}

Keywords

oral pathology; pediatrics; diseases; prevalence.

\section{RESUMEN}

Introducción: las patologías orales que se pueden presentar en niños son muy diversas y requieren un amplio conocimiento para poder diagnosticarlas. Objetivos: describir la frecuencia de patologías orales y maxilofaciales en pacientes de 0 a 18 años de edad que acudieron a la Fundación Hospital de la Misericordia (HOMI) en el periodo 2006-2014; además, relacionar estas patologías con características sociodemográficas. Metodología: estudio descriptivo de corte transversal. Se analizaron 277 historias clínicas de la Fundación Hospital de la Misericordia (HOMI) en pacientes de 0 a 18 años de edad, a los que se les diagnosticó alguna 
de las variedades de patología oral y maxilofacial, divididas así: lesiones quísticas cabeza/cuello, lesiones de la articulación temporomandibular (ATM), lesiones infecciosas, tumor benigno de cabeza y cuello, tumor maligno de cabeza y cuello y tumor odontogénico benigno. Se analizaron las características sociodemográficas. Resultados: las patologías más frecuentes fueron las lesiones infecciosas $(62,45 \%)$, seguidas de los tumores odontogénicos benignos (12,99\%). Conclusiones: la mayoría de los casos fueron del grupo de 10 a 14 años.

Palabras clave

pediatría; patología bucal; prevalencia; enfermedad.

\section{Introduction}

Oral pathologies that occur in children are very diverse, and it is necessary that odontologists and other health professionals have extensive knowledge to be able to diagnose them. Lesions can appear in the mucous membranes and in the soft tissue and bones, with different characteristics and etiologies; this makes the work of the clinician indispensable for the diagnosis and successful treatment of these diseases $(1,2,3,4)$.

During dental care, it is very important to have knowledge about the pathologies that may occur in children, as this will be the basis for early detection and timely referral, in order to provide a better management and prognosis of these diseases. $(5,6)$.

Lesions in children are different from those in adults; this is why more studies are necessary, since the most prevalent pathologies in adults should not be generalized as if they were present in the same way in children (7). Certain oral and maxillofacial diseases occur more frequently in children, and bring consequences that should be handled in a timely manner (8).

The study conducted by Fattahi et al. (9) on the prevalence of head and neck tumors in children under 12 years of age, showed that most of the tumors were benign and located mostly in the neck. Even so, there are few studies on the prevalence of oral and maxillofacial pathologies in pediatric patients.

A study conducted in Thailand by Dhanuthai et al. (10), showed that the greatest number of lesions in pediatric patients was found in the cystic category, followed by inflammatory and tumor lesions. There were also differences in the prevalence according to sex: there are pathologies that are reported more in women, such as head and neck benign tumors, while a higher prevalence of malignant tumors was found in men. This was concluded in the study by Abdulai et al. (1), on head and neck tumors in Ghanaian children.

In relation to Colombia, a study on the frequency of benign odontogenic tumors was carried out at the Hospital de la Misericordia (HOMI). A nine-year retrospective study conducted by Peña et al. (11), was the first performed in this pediatric institution, and constituted a very important basis for the present research.

There are differences between the different studies; this is because the criteria and variables used differ from one study to another $(12,13,14)$. It is necessary that knowledge about oral and maxillofacial pathology be supported on epidemiological bases. For this reason, we set out to describe the frequency of oral and maxillofacial pathologies in patients aged 0-18 years who attended the Maxillofacial Surgery Service of the Fundación Hospital de la Misericordia during the period 2006-2014, and to relate the most frequent oral and maxillofacial pathologies with sociodemographic characteristics.

\section{Methodology-Statistics}

The study was descriptive, cross-sectional, with an analysis of data collected from the ISIS database. It contained information of 277 medical records of the HOMI, of patients aged 0-18 years, attended between 2006 and 2014 .

The information in the medical records included the following: female and male patients aged 0.18 years who were arranged into 0.4 years, 5-9 years, 10-14 years, 15-18 years age groups, and those who were diagnosed with some type of oral and maxillofacial pathology, divided as follows: head/neck cystic lesions, temporomandibular joint (TMJ) lesions, 
infectious lesions, benign head and neck tumor, malignant head and neck tumor, benign odontogenic tumor, and those admitted to the HOMI in the period between January 2006 and December 2014.

The information of the medical records was organized in a unified table in which the basic data of the medical record, number of the record, sex, age, histopathological diagnosis, affected area and structures, presence or not of sensory alterations, pain, were recorded. Exclusion criteria were medical records with incomplete data or reports with dubious diagnoses.

The sociodemographic characteristics were analyzed as follows: sex and age, and the most frequent oral and maxillofacial pathologies were related to each of these characteristics, with the location and the presence or absence of paresthesia and pain. The statistical analysis was performed by Pearson and $\mathrm{chi}^{2}(\mathrm{p}<0.05)$ with the SPSS Statistics software.

\section{Results}

We analyzed 277 medical records that had been reviewed between January 2006 and December 2014. The following results were found:

The most frequent head and neck pathologies that occurred at the HOMI were infectious lesions, a $62.45 \%$, followed by benign odontogenic tumors, corresponding to $12.99 \%$, benign head and neck tumors, $10.10 \%$, and malignant head and neck tumors, head and neck cysts, TMJ lesions and skin lesions, which had lower frequency percentages (Table 1).

\section{Table 1}

Frequency of head and neck pathologies at the HOMI, 2006-2014

\begin{tabular}{|l|r|r|}
\hline Global histopathological diagnosis & Frequency & Percentage \\
\hline Head-Neck Cysts & 11 & 3.97 \\
\hline TMJ lesions & 5 & 1.80 \\
\hline Infectious lesions & 173 & 62.45 \\
\hline Skin lesions & 4 & 1.44 \\
\hline Head and neck benign tumors & 28 & 10.10 \\
\hline Head and neck malignant tumors & 20 & 7.22 \\
\hline Benign odontogenic tumors & 36 & 12.99 \\
\hline Total & 277 & 100.00 \\
\hline
\end{tabular}

Regarding sex, in general the male-female relationship was $2: 1$, men presented $66.42 \%$ of the pathologies evaluated, and women, 33.5\%.

According to the report of the Department of Pathology of the HOMI, the age group with the highest frequency of head and neck pathologies was that of $10-14$ years, with $31.05 \%$; followed by patients aged $0-4$ years, with a frequency of $26.35 \%$; patients aged 5-9 years, with $26.35 \%$; and patients $15-18$ years old, with $18.05 \%$.

Regarding the relationships between age and sex, the age group with the highest frequency of head and neck pathologies in both men and women was that of 10-14 years of age. There was no significant difference between the age groups regarding the presence of pathologies with respect to sex (Table 2).

Table 2

Age groups and sex of patients with head and neck pathologies, 2006-2014

\begin{tabular}{|l|r|r|r|r|r|}
\hline \multirow{2}{*}{ Sex } & \multicolumn{4}{|c|}{ Age Groups } & \multirow{2}{*}{ Total } \\
\cline { 2 - 6 } & $\mathbf{0 - 4}$ & $\mathbf{5 - 9}$ & $\mathbf{1 0 - 1 4}$ & $\mathbf{1 5 - 1 8}$ & \\
\hline \multirow{2}{*}{ Male } & 48 & 46 & 58 & 32 & 184 \\
\cline { 2 - 6 } & 26.09 & 25 & 31.52 & 17.39 & 100 \\
\hline \multirow{2}{*}{ Female } & 25 & 22 & 28 & 18 & 93 \\
\cline { 2 - 6 } & 26.88 & 23.66 & 30.11 & 19.35 & 100 \\
\hline \multirow{2}{*}{ Total } & 73 & 68 & 86 & 50 & 277 \\
\cline { 2 - 6 } & 26.35 & 24.55 & 31.05 & 18.05 & 100 \\
\hline
\end{tabular}

On the other hand, infectious lesions occurred with a frequency of $32.8 \%$ in women, and of $67.2 \%$ in men. In the category of odontogenic tumors, the percentage frequency in women was $34.3 \%$, whereas in men it was $65.7 \%$. These two categories of pathologies were the most frequent in both women and men (Table 3). With respect to the 28 cases of benign head and neck tumors, 19 were diagnosed in men and the remaining 9 cases in women. 
Table 3

Relationship between sex and diagnoses of head and neck pathologies, 2006-2014

\begin{tabular}{|l|l|r|r|r|}
\hline \multirow{2}{*}{\multicolumn{2}{|c|}{ Pathology }} & \multicolumn{2}{|c|}{ Sex } & \multirow{2}{*}{ Total } \\
\cline { 3 - 5 } & \multicolumn{1}{|c}{ F } & \multicolumn{1}{|c|}{ M } & \\
\hline \multirow{2}{*}{ Head and neck cystic lesion } & $\mathrm{n}$ & 6 & 5 & 11 \\
\cline { 2 - 5 } & $\%$ & 54.5 & 45.5 & 100 \\
\hline \multirow{2}{*}{ TMJ lesion } & $\mathrm{n}$ & 0 & 5 & 5 \\
\cline { 2 - 5 } & $\%$ & 0 & 100 & 100 \\
\hline \multirow{2}{*}{ Infectious lesion } & $\mathrm{n}$ & 57 & 117 & 174 \\
\cline { 2 - 5 } & $\%$ & 38.2 & 67.2 & 100 \\
\hline \multirow{2}{*}{ Skin lesion } & $\mathrm{n}$ & 2 & 2 & 4 \\
\cline { 2 - 5 } & $\%$ & 50 & 50 & 100 \\
\hline \multirow{2}{*}{ Head and neck benign tumor } & $\mathrm{n}$ & 9 & 19 & 28 \\
\cline { 2 - 5 } & $\%$ & 32 & 68 & 100 \\
\hline \multirow{2}{*}{ Head and neck malignant tumor } & $\mathrm{n}$ & 7 & 13 & 20 \\
\cline { 2 - 5 } & $\%$ & 35 & 65 & 100 \\
\hline \multirow{2}{*}{ Benign odontogenic tumor } & $\mathrm{n}$ & 12 & 23 & 35 \\
\cline { 2 - 5 } & $\%$ & 34.3 & 65.7 & 10 \\
\hline \multirow{2}{*}{ Total } & $\mathrm{n}$ & 93 & 184 & 277 \\
\cline { 2 - 5 } & $\%$ & 33.57 & 66.42 & 100 \\
\hline
\end{tabular}

Regarding head and neck malignant tumors, of the 20 cases, 13 occurred in men, 65\%; in women, the frequency was $35 \%$. In the category of head and neck cystic lesions, 6 of the 11 cases occurred in women, which corresponded to a percentage frequency of $54.5 \%$, whereas in men there were 5 cases, with a frequency of $45.5 \%$. It is the only category where there were more cases in women than in men (Table 3).

In the category of TMJ lesions, the 5 cases occurred in men. There were 4 cases of skin lesions, 2 in men and 2 in women (Table 3). With regard to the relationship between the pathology and the age groups, of the 11 cases of cystic lesion that occurred, 5 were in the 10-14 years age group $(45.5 \%)$, followed by patients aged 0.4 years $(27.30 \%)$. In the $5-9$ and $15-18$ years age groups there was a lower percentage of cystic lesions (Table 4).

With regard to the 5 cases of TMJ lesions, the age group with the highest frequency of this pathology was that of $10-14$ years, a $60 \%$, followed by the 5-9 and 15-18 years age groups, who each presented one case (Table 4).
Table 4

Relationship between age with diagnoses of head and neck pathology, 2006-2014

\begin{tabular}{|c|c|c|c|c|c|c|c|}
\hline \multirow{2}{*}{\multicolumn{2}{|c|}{ Pathology }} & \multicolumn{5}{|c|}{ Age Group } & \multirow{3}{*}{\begin{tabular}{|r|} 
Total \\
11 \\
\end{tabular}} \\
\hline & & & $0-4$ & $5-9$ & $10-14$ & 15-18 & \\
\hline \multirow{2}{*}{ Head and neck cystic lesion } & \begin{tabular}{|l|} 
Count \\
\end{tabular} & 0 & 3 & 2 & 5 & 1 & \\
\hline & \% within the illness & 0.00 & 27.30 & 18.20 & 45.50 & 9.10 & 100.00 \\
\hline \multirow{2}{*}{ TMJ lesion } & \begin{tabular}{|l|} 
Count \\
\end{tabular} & 0 & 0 & 1 & 3 & 1 & 5 \\
\hline & \% within the illness & 0.00 & 0.00 & 20.00 & 60.00 & 20.00 & 100.00 \\
\hline \multirow{2}{*}{ Infectious lesion } & \begin{tabular}{|l|} 
Count \\
\end{tabular} & 0 & 52 & 47 & 51 & 24 & 174 \\
\hline & \% within the illness & 0.00 & 29.90 & 27.00 & 29.30 & 13.80 & 100.00 \\
\hline \multirow{2}{*}{ Skin lesion } & \begin{tabular}{|l|} 
Count \\
\end{tabular} & 0 & 2 & 1 & 1 & 0 & 4 \\
\hline & $\%$ within the illness & 0.00 & 50.00 & 25.00 & 25.00 & 0.00 & 100.00 \\
\hline \multirow{2}{*}{ Head and neck benign tumor } & \begin{tabular}{|l|} 
Count \\
\end{tabular} & 1 & 8 & 6 & 8 & 5 & 28 \\
\hline & \begin{tabular}{|l|}
$\%$ within the illness \\
\end{tabular} & 3.60 & 28.60 & 21.40 & 28.60 & 17.90 & 100.00 \\
\hline \multirow{2}{*}{ Head and neck malignant tumor } & \begin{tabular}{|l|} 
Count \\
\end{tabular} & 0 & 6 & 6 & 8 & 0 & 20 \\
\hline & $\%$ within the illness & 0.00 & 30.00 & 30.00 & 40.00 & 0.00 & 100.00 \\
\hline \multirow{2}{*}{ Benign odontogenic tumor } & Count & 0 & 1 & 5 & 10 & 19 & 35 \\
\hline & \begin{tabular}{|l|}
$\%$ within the illness \\
\end{tabular} & 0.00 & 2.90 & 14.30 & 28.60 & 54.30 & 100.00 \\
\hline \multirow{2}{*}{ Benign tumor } & Count & 1 & 72 & 68 & 86 & 50 & 277 \\
\hline & \begin{tabular}{|c|}
$\%$ within the illness \\
\end{tabular} & 0.40 & 26.00 & 24.50 & 31.00 & 18.10 & 100.00 \\
\hline \multirow{2}{*}{ Total } & $\%$ within the illness & 100.00 & 100.00 & 100.00 & 100.00 & 100.00 & 100.00 \\
\hline & $\%$ of the total & \begin{tabular}{|l|}
0.40 \\
\end{tabular} & 26.00 & 24.50 & 31.00 & 18.10 & 100.00 \\
\hline & lesions & & & & & & an \\
\hline
\end{tabular}
approximately equal frequency in the $0-4$ and 10-14 years age groups, with percentage frequencies of 29.30 and 29.9 , respectively. $27 \%$ corresponded to infectious lesions in patients aged 5-9 years, whereas in the of 15-18 years age group the pathology occurred less frequently (Table 4).

There were 4 cases of skin lesions. 2 of these were in the $0-4$ years age group, representing 50\% of the frequency (Table 4). There was a higher frequency of head and neck benign tumors in the $0-4$ years age group, which represents $32.14 \%$, followed by the 10-14 years age group, in which there were 8 cases $(28.60 \%)$. Patients aged $15-18$ years had the lowest number of cases in this category (Table 4).

Of the 20 cases of head and neck malignant tumor category, 8 corresponded to the 10-14 years age group (40\%). In the $0-4$ and $5-9$ years age groups there was the same number of cases, 6 in each, totaling $60 \%$ of the frequency for this pathology. There were no cases in patients aged 15-18 years (Table 4$)$.

There was a higher frequency of benign odontogenic tumors in patients aged 15-18 years, with $54.30 \%$, followed by patients aged $10-14$ years, who had a percentage frequency of $28.60 \%$. In the $0-4$ years age group only one case occurred, which represented $2.9 \%$ (Table 4).

Of the 277 cases, 86 occurred in the 10-14 years age group, which constitute $31 \%$ of the total sample. Patients aged $0-4$ years had the second highest percentage frequency $(26.5 \%)$. 
The group with the fewest pathologies was the 15-18 years age group (Table 4).

Infectious lesions had the highest percentages in all age groups (Table 4). According to the Pearson chi2 test $(0)$, there is a statistically significant association between the age groups and the pathologies presented.

Regarding the location, there were 11 cases of cystic head and neck lesion: 3 located in the TMJ and in the neck, and 3 in the oral cavity and soft tissues, representing a percentage of 27.3 each. Of the 5 cases of TMJ lesions, $60 \%$ were located in the TMJ region and the neck. Regarding infectious lesions, the majority were located in the nasal cavity, and the percentage frequency in this area was $64.9 \%$; the following areas where these lesions occurred most frequently were the oral cavity and soft tissues. Regarding skin lesions (nevus), 75\% were located in the TMJ and the neck. It was also observed that $46.40 \%$ of the head and neck benign tumors were located in the oral cavity, whereas most of the head and neck malignant tumors were located in the nasal cavity (45\%). With regard to benign odontogenic tumors, $42.90 \%$ occurred in the posterior mandibular area, and $22.90 \%$ were located in the posterior maxillary area (Table 5).

\section{Table 5}

Relationship between the disease and its anatomical location

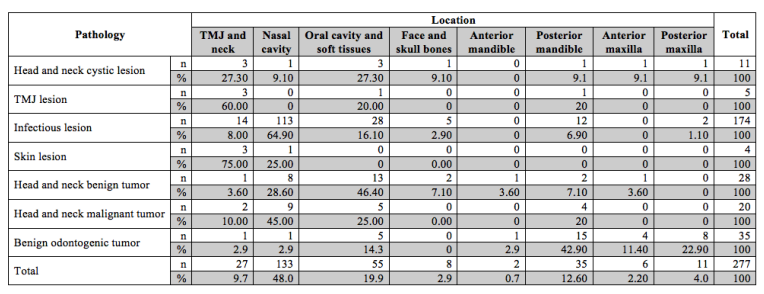

According to the Pearson $\mathrm{chi}^{2}$ test $(0)$, there is a statistically significant association between the patient's pathology and its location. However, $18.20 \%$ of the patients who presented head and neck cystic lesions reported pain. It can also be seen that the 5 patients who presented TMJ lesion presented pain (Table 6). 50\% of the cases of infectious lesions presented pain, and the other $50 \%$ did not present. With regard to skin lesions, patients did not present pain (Table 6).
Table 6

Relationship between disease and presence of pain

\begin{tabular}{|c|c|c|c|c|}
\hline \multirow{2}{*}{\multicolumn{2}{|c|}{ Pathology }} & \multicolumn{2}{|c|}{ Pain } & \multirow{3}{*}{$\begin{array}{r}\text { Total } \\
11 \\
\end{array}$} \\
\hline & & \multirow{2}{*}{$\begin{array}{r}\text { No } \\
9 \\
\end{array}$} & \multirow{2}{*}{$\begin{array}{r}\text { Yes } \\
2 \\
\end{array}$} & \\
\hline Head and neck & Count & & & \\
\hline cystic lesion & $\%$ within the illness & 81.80 & 18.20 & 100.00 \\
\hline \multirow{2}{*}{ TMJ lesion } & Count & 0 & 5 & 5 \\
\hline & $\%$ within the illness & 0.00 & 100.00 & 100.00 \\
\hline \multirow{2}{*}{ Infectious lesion } & Count & 87 & 87 & 174 \\
\hline & $\%$ within the illness & 50.00 & 50.00 & 100.00 \\
\hline \multirow{2}{*}{ Skin lesion } & Count & 4 & 0 & 4 \\
\hline & $\%$ within the illness & 100.00 & 0.00 & 100.00 \\
\hline \multirow{2}{*}{$\begin{array}{l}\text { Head and neck } \\
\text { benign tumor }\end{array}$} & Count & 17 & 11 & 28 \\
\hline & $\%$ within the illness & 60.70 & 39.30 & 100.00 \\
\hline \multirow{2}{*}{$\begin{array}{l}\text { Head and neck } \\
\text { malignant tumor }\end{array}$} & Count & 5 & 15 & 20 \\
\hline & $\%$ within the illness & 25.00 & 75.00 & 100.00 \\
\hline \multirow{2}{*}{$\begin{array}{l}\text { Benign odontogenic } \\
\text { tumor }\end{array}$} & Count & 13 & 22 & 35 \\
\hline & $\%$ within the illness & 37.10 & 62.90 & 100.00 \\
\hline \multirow{4}{*}{ Total } & Count & 135 & 142 & 277 \\
\hline & $\%$ within the illness & 48.70 & 51.30 & 100.00 \\
\hline & $\%$ within pain & 100.00 & 100.00 & 100.00 \\
\hline & $\%$ of the total & 48.70 & 51.30 & 100.00 \\
\hline
\end{tabular}

Of the 28 cases of head and neck benign tumors, $39.39 \%$ presented pain. Of the 20 cases of head and neck malignant tumors, 15 reported pain $(75 \%)$. There were 35 cases of benign odontogenic tumor, 22 of which reported pain (Table 6).

Of the 277 patients who presented any of these head and neck pathologies, 142 reported pain $(51.30 \%)$. However, of the 142 cases, 87 presented infectious lesions, which constitutes $61.30 \%$ of the patients with this symptomatology (Table 6). According to the Pearson chi2 test $(0.001)$, there is a statistically significant association between the patients' pathologies and the presence of pain.

Of the 5 cases of TMJ lesion, 1 had paresthesia, which corresponds to 20\%. As for the 174 patients who presented infectious lesions, only 4 had paresthesia $(2.30 \%)$. Of the 28 cases of benign head and neck tumors, only 2 experienced paresthesia, equivalent to $7.10 \%$. On the other hand, of the 20 patients who presented head and neck malignant tumors, 5 presented paresthesia, which constitutes a percentage frequency of 25. The frequency of paresthesia in patients with benign odontogenic tumors was 22, $8 \%$ (Table 7 ). 
Table 7

Relationship between the disease and the presence of paresthesia

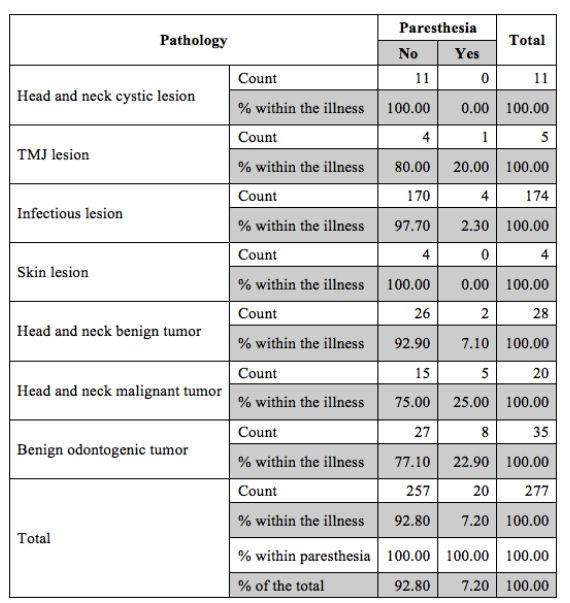

Of the 277 cases with any of the head and neck pathologies studied, 20 presented paresthesia, having a percentage frequency of 7.20. In the patients who presented paresthesia, the pathology that occurred most frequently was benign odontogenic tumors, representing $40 \%$ of the total (Table 7). According to the Pearson chi ${ }^{2}$ test, there is a statistically significant association between the patients' pathologies and the presence of paresthesia.

\section{Discussion}

The most frequent head and neck pathologies occurred in patients treated at the HOMI were infectious lesions, representing $62.45 \%$. In second place were the benign odontogenic tumors, with $12.99 \%$. Benign head and neck tumors constituted $10.10 \%$, whereas the frequency of malignant head and neck tumors of was $7.22 \%$. Regarding head and neck cysts, the prevalence was $3.97 \%$.

The study by Lapthanasupkul et al. (7), conducted in Thailand, showed that the most common oral and maxillofacial pathologies in pediatric patients were odontogenic cysts and tumors $(35.5 \%)$, followed by inflammatory and reactive lesions (17\%). Now, the study by Lei et al. (15), conducted in Taiwan, showed that the highest percentage of the 1,023 biopsies analyzed was in the group of inflammatory and reactive lesions $(44.10 \%)$, followed by groups of tumor lesions (22.45\%) and cystic lesions. (19.16\%). The study conducted in Thailand by Dhanuthai et al. (10), showed that the pathologies that occurred most frequently were cystic (35.01\%), inflammatory reactive $(34.77 \%)$, and tumor $(30.22 \%)$ lesions. It can be observed that in the three studies, the most frequent categories were the inflammatory, tumor and cystic lesions, which is similar to what was found in the HOMI.

We found in the HOMI that TMJ lesions and skin lesions had a lower frequency percentage than the mentioned categories, with frequencies of $1.80 \%$ and $1.44 \%$, respectively.

Regarding sex, the male-female ratio was $2: 1$; men presented $66.42 \%$ of the pathologies evaluated, and women $33.57 \%$. There was no significant relationship between sex and the frequency of the pathologies. This relationship was consistent with that of other studies, such as that of Dhanuthai et al. (10) and Lei et al. (15).

Regarding age, the age group that presented the highest frequency of head and neck pathologies, reported by the Department of Pathology of the HOMI, was the 10-14 years age group, with a percentage of 31.05, followed by patients aged $0-4$ years, with a frequency of $26.35 \%$. The $15-18$ years age group had the lowest frequency of pathologies, constituting $18.05 \%$. Although the different studies do not have the same division of age groups as the present study, it was observed that most of the pathologies occurred in patients aged 11-15 years, as shown by the studies by Lapthanasupkul et al. (7), and by Lei et al. (15). Even so, there are differences, since studies show that the frequency of pathologies increases with age $(7,10,15,16,17)$, and from what is reported in the HOMI it can be seen that in the 15-18 years age group the frequency was lower than in the other groups. These differences may be due to the sample size and the age categorization.

Regarding signs and symptoms, in the present study we evaluated the presence of pain and paresthesia. Of the 277 patients, 142 reported pain $(51.30 \%)$. However, of these 142 cases, 87 had infectious lesions, which constitutes $61.30 \%$ 
of patients with this symptomatology. With regard to the 277 cases, 20 presented paresthesia (7.20\%). As for the patients who presented paresthesia, the most frequent pathology was that of benign odontogenic tumors, representing $40 \%$ of the total. These high percentages of symptoms may be due to the fact that the health system is not efficient, and pathologies are diagnosed and treated when they already present symptoms and are in more advanced stages.

A statistically significant association was found between the pathologies and their location. It can be observed that of the 11 cases of head and neck cystic lesions, 3 were located in the TMJ and the neck, and 3 in the oral cavity and soft tissues, a percentage of 27.3 for each. Of the 5 cases of TMJ lesions, $60 \%$ were located in the TMJ and neck region. With respect to infectious lesions, the majority was located in the nasal cavity (the percentage frequency in this region was 64.9). The next area with greater frequency of these lesions was the oral cavity and soft tissues, with $16.10 \% .75 \%$ of the skin lesions (nevus) were located in the TMJ and neck region. It can also be seen that $46.40 \%$ of the benign head and neck tumors were located in the oral cavity, whereas the head and neck malignant tumors were located in the nasal cavity (45\%). With respect to benign odontogenic tumors, $42.90 \%$ were located in the posterior mandibular region, followed by those located in the posterior maxilla region, with $22.90 \%$. These statistically significant associations are evidenced in other studies, such as that of Lei et al. (15).

\section{Conclusions}

The most frequent head and neck pathologies that occurred in patients treated at the HOMI were infectious lesions, followed by benign odontogenic tumors and benign head and neck tumors.

As for sex, the male-female ratio was 2:1.

The age group that presented the highest frequency of head and neck pathologies was that of patients aged 10-14 years, followed by patients aged $0-4$ years. The frequency of pathologies diagnosed decreased in patients aged 15-18 years, with the exception of benign odontogenic tumors, which presented a higher percentage in this age group.

In all age groups, infectious lesions had the highest percentages of frequency.

Benign head and neck tumors occurred more frequently in the $0-4$ years age group, whereas in the category of malignant head and neck tumors, the frequency was higher in the 10-14 years age group.

The most frequent locations of head and neck cystic lesions were the TMJ and the neck, and the oral cavity and soft tissues. Regarding TMJ lesions, the majority of cases were located in the TMJ and neck region. With regard to infectious lesions, most were located in the nasal cavity, followed by the oral cavity and soft tissues. Skin lesions were located in the TMJ and neck region. Benign head and neck tumors were located in the oral cavity, whereas malignant head and neck tumors were located mostly in the nasal cavity. With regard to benign odontogenic tumors, they occurred more frequently in the posterior mandibular area, followed by the posterior maxillary area.

There is a statistically significant association between the pathology and the location of the lesions and the signs and symptoms of pain and paresthesia.

\section{Recommendations}

It is necessary to make a meaningful comparison and unify the methodological criteria; it is also necessary to categorize the pathology with more specific groups, and to limit the age variable so that all studies manage a population with similar ages.

It is important to adapt ourselves to the ICD-10 codes, to be specific in the head and neck tumor pathology diagnoses.

In order to provide a national epidemiological benchmark, it is important to conduct similar studies in hospitals that treat this type of pathologies, and thus have beneficial tools to assess the behavior of these pathologies in the 
pediatric population of the country. The present study can be a benchmark in Colombia, and serve as a guide for similar studies in healthcare institutions.

\section{Acknowledgements}

We wish to express our thanks to the Scientific Direction of the HOMI and to the Oral and Maxillofacial Surgery Service.

\section{References}

1. Abdulai AE, Nuamah IK, Gyasi R. Head and neck tumours in Ghanaian children: A 20 year review. Int J Oral Maxillofac Surg. 2012;41(11):1378-82.

2. Rioboo-Crespo M del R, Planells-del Pozo P, Rioboo-García R. Epidemiology of the most common oral mucosal diseases in children. Med Oral Patol Oral Cir Bucal. 2005;10(5):376-87.

3. Martins-Filho PR, de Santana Santos T, Piva MR, da Silva HF, da Silva LC, Mascarenhas-Oliveira AC, et al. A Multicenter Retrospective Cohort Study on Pediatric Oral Lesions. J Dent Child (Chic). 2015;82(2):84-90.

4. Thacker MM. Malignant soft tissue tumors in children. Orthop Clin North Am. 2013;44(4):657-67.

5. Albright JT, Topham AK, Reilly JS. Pediatric head and neck malignancies: US incidence and trends over 2 decades. Arch Otolaryngol Head Neck Surg. 2002;128(6):655-9.

6. Jones AV, Franklin CD. An analysis of oral and maxillofacial pathology found in children over a 30-year period. Int J Paediatr Dent. 2006;16(1):19-30.

7. Lapthanasupkul P, Juengsomjit R, Klanrit P, Taweechaisupapong S, Poomsawat S. Oral and maxillofacial lesions in a Thai pediatric population: a retrospective review from two dental schools. J Med Assoc Thai. 2015;98(3):291-7.

8. Brierley DJ, Chee CK, Speight PM. A review of paediatric oral and maxillofacial pathology. Int J Paediatr Dent. 2013;23(5):319-29.

9. Fattahi S, Vosoughhosseini S, Moradzadeh Khiavi M, Mahmoudi SM, Emamverdizadeh P, Noorazar SG, et al. Prevalence of head and neck tumors in children under 12 years of age referred to the Pathology Department of Children's Hospital in Tabriz during a 10-year Period. J Dent Res Dent Clin Dent Prospects. 2015;9(2):96-100.

10. Dhanuthai K, Banrai $M$, Limpanaputtajak S. A retrospective study of paediatric oral lesions from Thailand. Int J Paediatr Dent. 2007;17(4):248-53.

11. Peña CP, Leonel EL, Guzmán CD, Esquivel DL, Rodríguez M, Bustillo J. Frecuencia de tumores odontogénicos benignos en la Fundación Hospital de la Misericordia (Bogotá, Colombia): un estudio retrospectivo a nueve años. Unv Med. 2016;57(4):467-79. doi: http://doi.org/10.11144/Javeriana. umed57-4.ftob

12. Chen YK, Lin LM, Huang HC, Lin CC, Yan YH. A retrospective study of oral and maxillofacial biopsy lesions in a pediatric population from southern Taiwan. Pediatr Dent. 1998;20(7):404-10.

13. Chi AC, Neville BW. Odontogenic cysts and tumors. Surg Pathol Clin. 2011;4(4):1027-91.

14. Elarbi M, El-Gehani R, Subhashraj $\mathrm{K}$, Orafi M. Orofacial tumors in Libyan children and adolescents: A descriptive study of 213 cases. Int J Pediatr Otorhinolaryngol. 2009;73(2):237-42.

15. Lei F, Chen JY, Lin LM, et al. Retrospective study of biopsied oral 
and maxillofacial lesions in pediatric patients from southern Taiwan. J Dent Sci. 2014; 9:351-8.

16. Lima Gda S, Fontes ST, de Araujo LM, Etges A, Tarquinio SB, Gomes AP. A survey of oral and maxillofacial biopsies in children: A single-center retrospective study of 20 years in Pelotas-Brazil. J Appl Oral Sci. 2008;16(6):397-402.

17. Khademi B, Taraghi A, Mohammadianpanah M. Anatomical and histopathological profile of head and neck neoplasms in Persian pediatric and adolescent population. Int $\mathrm{J}$ Pediatr Otorhinolaryngol. 2009;73(9):1249-53. 